\title{
Identifying and Ranking Performance Measurement Indicators of Hospitals Based on Balanced Scorecard
}

\author{
Mohammad Nazaripour \\ Department of Accounting, University of Kurdistan, Sanandaj, Iran; E-mail: mnazaripour@yahoo.com
}

\begin{abstract}
Doi:10.5901/mjss.2015.v6n6s2p600
\end{abstract}
\begin{abstract}
This study attempts to identify and rank performance measurement indicators of hospitals using balanced scorecard. The population of this study was experts on the scorecard. Using Cochran Formula, 145 people were selected as sample. The period of this study was first quarter 2014. The needed data was gathered through a questionnaire. Friedman test and factor analysis were used to analyze the gathered data. According to the research findings, in each four perspective of the balanced scorecard, the following criteria had a high priority. In financial perspective two indicators of reducing health care costs, and attracting more customers, in internal processes perspective three indicators including having an appropriate organizational chart, improving personnel safety standards and having adequate facilities, in learning and growth perspective motivating employees and in customer perspective two indicators of customer satisfaction and treating respectfully with them.
\end{abstract}

Keywords: Balanced Scorecard, Performance Measurement, Hospital, Iran

\section{Introduction}

The old methods of performance evaluation were focused on cost and profit factors; hence do not have the ability of supply chains. This research aims to establish and design the complete evaluation indicators within the framework of four aspects balanced scorecard (BSC) approach for hospitals. BSC approach is a known approach that is assumed as the traditional financial standard supplementary in the field of organizations ' performance evaluation. Balance word refers to the balance between financial and non-financial indicators, leading and non-leading indicators and internal and external aspects of the performance evaluation. BSC approach is a supplementary approach that includes many performing indicators such as financial and non-financial indicators.

BSC provides a fast setting of measurement but with a comprehensive view for senior managers and considers the operational performance in addition to financial performance. This method is a management technique that helps organizations 'managers to study the activities and growing or passive approach of the organization from different perspectives. In fact the BSC states the amount of organizations' targets achievement. This technique evaluates the level of organization`s strategy effectiveness with detecting targets` achievement indicators. Balanced scorecard is a set of business unit targets in line with financial indicators. The Executive Director of the organization knows how indicators in the business unit creates for current and future customers and also how they should improve the internal capabilities and investing on personnel, systems and methods necessary for future performance upgrades. Balanced scorecard creates the important value making activities through the creation of skills and organizational corporate partnerships. While the mere attention to the financial aspect can make to achieve profit in the short term, balanced scorecard reveals clearly valuable actuators that create competitive performance and achieving long-term profits. Balanced scorecard stresses on the subject that financial and non-financial indicators should be part of the information system for employees in all levels of the organization. The operational and production line staff should touch decisions and activities financial results. Senior executives should view long-term financial success.

Targets and indicators for the balanced scorecard are resulted from financial performance indicators. They are derived from a top-down process on the bases of business unit mission and strategy. Balanced scorecard is something more than a functional assessment system or a tactical system. Innovative organizations use scorecard as a strategic management system to control the long-term strategies. They use scorecard for the implementation of successful key management processes. In fact, BSC in addition to financial measures pays attention to experiences of customers, staff improvement and the process efficiency growth. Paying attention to these four aspects at the same time makes it possible for the Organization to provide a deeper and better understanding of its performance process and with an awareness of their strengths and weaknesses in all organizational aspects, implements its continuous improvement of its 
performance that would eventually lead to higher competitive position compared to the other competitors for the organization. BSC prevents the problems in a unit resulted from ignoring the other parts. In addition, the managers who uses BSC, gain necessary insight regarding to the experiences of their employees. The learning and growth measures give the executives the necessary information about workers satisfaction and their non- movement from the organization which both these factors leads to better profit and gaining. (Kaplan \& Norton, 1993).

Organizations have to use performance evaluating systems in order to decision making support in excellent management and the operational level. The old performance evaluation methods that were on the basis of financial criteria and cost accounting has many flaws. Including that they are historical and retrospective, do not have the ability to predict the short term performance or award non-correct behaviors and etc. The BSC criteria was first introduced by Kaplan and Norton (1992) in an article with the name of balanced scorecard indicators which measure the performance. In this article, BSC is defined as a tool for performance measurement. Kaplan and Norton after this research insist that chosen and multiple indicators of performance should be related to the strategic targets. BSC is one of 75 effective ideas that are offered by Harvard university business studies in 20th century. According to Maltz et al (2003), BSC is a multidimensional frame that changes the company strategy to special measurable targets. Similarly Bremser and White (2000)say that BSC is an integrated strategic performance management framework. Martinsons (Martinsons, 1993) describes BSC as a decision supporting tool in strategic management level. Niven (2002) refers that BSC is a set of performance criteria that can be caused by the business strategy. Right now, complete and comprehensive research has not yet been carried out in Iran to respond to this question and although the research in conjunction with the balanced scorecard has been done but no comparison has been done between the relationship of balanced scorecard and the unofficial cards. Balanced scorecard is a system to evaluate the performance that takes to account the four financial, the customer, internal processes and learning and growth perspectives. (Kaplan \& Norton, 2006, p. 11)The point is that how using BSC compare to traditional approach, improves managers performance?

\subsection{Research necessity and importance}

Fast growing of technology, massive wave of information and the development of a variety of special services, has provided more necessity of planning principles and comprehensive policy for organizations. But the logistic guarantee for these policies, yet have been established wisely, is the exact and consistent evaluation and reviewing the methods. Performance evaluation policies in hospitals can be optimized in line with the overall strategies and better performance of control mechanism improvement deliver important information about hospital performance units and its adjustment programs to the managers.

\subsection{Research targets}

The main objective of this study is to identify the indicators of performance evaluation on the basis of balanced scorecard in hospitals. In this regard, while trying to offer a strong literature in the field of BSC approach, highly influential indicators in the field of performance balanced assessment in hospitals will be identified and ranked.

\subsection{Research's words performing definitions}

Balanced scorecard: A system to evaluate the performance that takes to account four financial, customer, internal processes, learning and growth perspectives.

Financial perspective: This perspective considers maximizing the profit as the ultimate goal of an enterprise.

Customer perspective: This perspective is as a distinct value-based strategy available to the customer.

Perspective Internal Process: It increases the way to develop human, organizational and information capital for differentiating the offer able value to customers and also improves the processes and reduces efficiency costs.

Growth Perspective and Learning: This perspective can be intangible assets strategy coordination namely human capital, access to the skills, talents guidelines as well as informational capital means accessing to information systems, networks and infrastructures.

\section{Literature Review}

Ansari et al (2009) a research was carried out in order to investigate the effects of efficacy management on the function of transmission Company according to balanced concessive card in transmission Company of Isfahan. It shows that 
efficacy management affects four function aspects (financial, customer, growth and learning, internal processes of business) more than medium level. So we can claim that there is a significant relation between efficacy management and four aspects of concessive card. Moeieddin et al (2010) a research was carried out in order to contrastively analyze the determination power of conventional criteria (return rate of assets, operational cash) and modern criteria (economical excess value) about evaluating the function of companies in metallurgy field. The results showed that there was a significant relation between economical excess value and return rate of assets. Also there was not any significant relation between operational cash and return rate of shares. Also there is no relation between determination power of conventional criteria functions and those of modern criteria. Zareie matin et al (2011) a research was carried out in order to investigate the relation between strategic attitude of company and organizational function using concessive card approach. The findings out of the relation between strategic dimensions and balanced concessive card shows that financial dimension of balanced concessive card is only in relation with analytical attitude. Analytical attitude has positive and significant relation with all dimensions of balanced concessive card. Hoque \& James (2000) carried out a research in Australian producer companies and investigated common using balanced evaluation among these companies. The purpose of this research was to investigate the relation between using evaluation balanced with the size of organization, life cycle of product, power of market and its effects on organization function. The results showed an important and positive relation between conventional criteria of balanced evaluation and better function. These researchers claimed that while their researches show the relation between non-financial criteria function and optimum function of companies, their study was not successful creating real dependency on balanced evaluation and also in making informal communication in which using balanced evaluation is necessary. Malina \& Selto (2001) carried out another study about a producing company. They examined the effectiveness of balanced evaluation in conveying strategic goals and as a tool to be used in contributing managerial controls. They found evidences for an indirect relation between managerial functions of balanced evaluation and optimizing the function according to the criteria of balanced evaluation. The managers were convinced in this research that developing the function according to balanced evaluation causes development in efficiency and profitability. Davis \& Albright (2004) carried out a research about the effects of implementation of balanced evaluation on the function of companies in an American bank. They implemented a balanced evaluation in four branches of bank and then after two years, compared the results of indices in these four branches to four branches that still used those conventional methods for evaluation. They found out that there is a significant relation between practically using there balanced evaluation and improving the function of these branches. Ittner et al (2003) presented different results and claimed that there is a negative relation between using balanced evaluation and financial operation. This study was carried out on financial service industry. These authors also found this point that more than $75 \%$ of companies announced that they do not trust non - financial evaluation models.

The first group of researches examines the power of operation evaluation in organizations' operation evaluation. The second group investigates evaluation method and analyzes its effects on organization's operation. The results of the first group show positive or negative operation evaluation on operation evaluation and the results of the second group show gross differences in results due to difference in implementation method of balance evaluation approach. The observations confirm this point that power or level of using balanced operation evaluation method affects the function of organization but its quality depends on usage method (Braam \& Nijssen, 2004, p. 34).

\section{Research Territory}

\subsection{Time zone}

The research time zone is since July to November 2013.

\subsection{Research territory}

The research territory is experts familiar to balanced evaluation cards in Iran's hospitals. This group of experts includes all influencing staff on hospital activities, including the Chairman, the Director, Deputy Vice-Chancellor, metron, treatment vice president, research and development deputy and etc...

\subsection{Statistical community definition}

The research statistical community has been the assembly of experts in Iran's hospitals who knows about BSC. To do this research and gathering experts votes, Delphi method has been used. In continue we will discuss the method details: 


\subsection{Delphi method}

Using the Delphi method is mainly with the aim of discovering creative and reliable ideas and providing the appropriate information or in order to make decisions. Delphi method is a structured process for collecting and classifying existing knowledge in the sight of a group of experts and reporters that is done through questionnaire distributed between these people and controlled received replies and comments. (Adler \& Ziglio, 1996). Delphi method is based on a dialectical research approach, namely is formed on the thesis (creation of opinion or comment), antithesis (the opposite opinion) and finally a synthesis (new agreement and consensus) that the synthesis itself turns into a new thesis. In Helmer's point of view (1977), Delphi is a communicational useful tool between a group of reporters that simplifies the formulation of group members 'votes. Wissema (1982) with an emphasis on the importance of the Delphi method, calls it as a method for a single criteria exploration to predict the future of the technology. He adds that Delphi is designed by the aim of making the experts discussion possible in a way that stops the entrance of the effect of mutual social behaviors that usually happen in group discussions and lead to a barrier against formation of ideas and opinions. Baldwin (1975) believes that in case of scientific knowledge lacking between decision makers, they have to decide on the basis of their direct understandings or experts votes. The basis and Foundation of the Delphi method or technique is that any scientific domain experts comments about the future, is the most anticipated. So unlike the work research methods, validity of the Delphi method, is not dependent on the number of participants in research but to the scientific validity of experts participated in the research. In Delphi research, the number of participants depends on how the research method is designed. In this method, councils of experts (the Panels), are formed that the interaction between its members would be performed by the researcher himself. Internal communications of participants are anonymous and opinions, predictions and desires are not attributed to their providers. The release of this information will be done without identification of the providers. In spite of considerable differences in the applying Delphi technique, Delphi research usually starts with a questionnaire designed by a small team being sent to a greater group of experts. The questionnaires are set in a way that makes it possible for the individuals to raise their individual reactions while understanding and finding out the issue. When the questionnaires are returned, the answers and reasons defined by the experts for their replies will be reviewed and summarized. In this way, over time and with the work progress, contacts' viewpoints will be matched with the subject presented. This process continues until the Union is formed about the comments or it is determined that the specialists have not reached an agreement. Delphi is not a serious and hard statistical method for future prediction Lack of sampling, uncertainty about future events, lack of a clear defined processes for Delphi studies performance, are only a few items that distinguish Delphi from controlled scientific methods. But Delphi is valuable especially for the issues which do not need accurate analyzing methods: For example when data are not enough or uncertain or real samples are not available or when gathering people and talking about an issue is hard. Since Delphi technique relies on anonymity, controlled reactions and statistical group response and therefore avoids entering outstanding individuals in discussion groups or pressure group to avoid conformity, with using this technique a valid Union of professionals can be made.

\section{Methods}

\subsection{Data gathering method}

To test the hypothesis in this study, a questionnaire has been used for examining the hypothesis. The prepared questionnaire has been embedded on the basis of research assumptions embedded in which four dimensions including financial, internal process, learning and growth, and customer aspects is designed based on Likert scale. Any item in this range (38 alternatives) consists of 5 items that are mentioned in following:

1) The choice I do agree completely, that scored 1.

2) The choice I do agree, that scored 2.

3) The choice I do agree to some extent that scored 3.

4) The choice I do not agree, that scored 4.

5) The choice I disagree completely, that scored 5.

In all stages of data analysis also 5 levels have been used.

Combination of questionnaire questions is mentioned in table 1. 
Table 1: Combination of the questionnaire questions

\begin{tabular}{|l|c|}
\hline Dimensions & Relating questions in questionnaire \\
\hline Financial dimension & $9-1$ \\
\hline Internal process dimension & $21-10$ \\
\hline Growth and learning dimension & $29-22$ \\
\hline Customer dimension & $38-30$ \\
\hline
\end{tabular}

\subsection{Questionnaires' consistency and reliability}

It should be considered that the foresaid questionnaire first was experimented to the limited number and its bugs and ambiguities were removed and organizing the content and its structure regulating was revised. Finally, in order to determine the validity of the questionnaire and regarding that the questions contained in the questionnaire evaluate precisely the variables and the subject of this research, the survey validity was confirmed by masters` opinion.

Different methods are used for calculating the consistency. The common statistic is Cronbach's Alpha. The value of Alpha coefficient is achieved by following formulae. (Arizi \& Farahani, 2009).

$\alpha=\left(\frac{j}{j-1}\right)\left(1-\frac{\sum \sigma_{j}^{2}}{\sigma^{2}}\right)$

A: Total test reliability coefficient

$\mathrm{J}$ : number of test segments

$\sigma^{2}:$ The variance of test scores

$\sigma^{2}$ : The variance of test

Here is the Cronbach's Alpha obtained from SPSS software:

Table 2: Alpha related to each of questions group relating to research hypothesis

\begin{tabular}{|c|c|l|c|}
\hline Row & \multicolumn{1}{|c|}{ Main Factors } & Minor factors & Cronbach's Alpha \\
\hline 1 & \multirow{2}{*}{\begin{tabular}{c} 
Balanced scorecard evaluation \\
\cline { 1 - 2 } dimension
\end{tabular}} & Financial dimension & 0.92 \\
\cline { 4 - 5 } & & Internal process dimension & 0.94 \\
\cline { 4 - 5 } & & Growth and learning dimension & 0.96 \\
\cline { 4 - 5 } & & Customer dimension & 0.79 \\
\hline
\end{tabular}

\section{Results}

\subsection{Data statistical analysis method}

Data analysis will be carried out in two separate descriptive and inferential methods as follow:

\subsubsection{Descriptive analysis:}

In this section, first General description of the characteristics of respondents like the education level, gender, service officer, etc....useful statistical charts such as a pie chart will be draw.

\subsubsection{Inferential analysis:}

In this section also Friedman rank test and factor analysis will be used.

\subsubsection{Factor analysis}

A collection of methods, to determine the scope variables that are linked together so that they can be grouped and as a result, instead of being analyzed as separate variables, be considered as hybrid variable or factor. Perhaps the most common type of used factor analysis in behavioral or social sciences is determining the social responses to a set of parameters used to measure the specific concept that can be grouped together for shaping an indicator of that concept. (Miles \& Banyard, 2007).To find out the estimation of parameters in factor analysis there are various methods. One of the most convenient methods is to use the original component methods. Each component has a variance that sum of all 
components variance equals variance of the whole. The number of extracted components is always the same number of variables included in the analysis. The first factor always describes the biggest share of the total variances, the second large contribution factor will explain variance that is not explained by the first factor and likewise the last factor represents the smallest share of the variance. Each variable has correlation with the other variables. Since the first factor explains the largest share of total variance, the first factor correlation with other variables would be the highest average, second factor goes to the next level and similarly for calculating total contribution of variance explained by each variable, easily twe've the changed variable on that factor, add the squares together to get the special values of the factor and divide these Special values on the variable. (Miles \& Banyard, 2007).

Finally our criterion for extracting main components is the same special amounts and we extract the values by amount of more than 1.

1. Sex

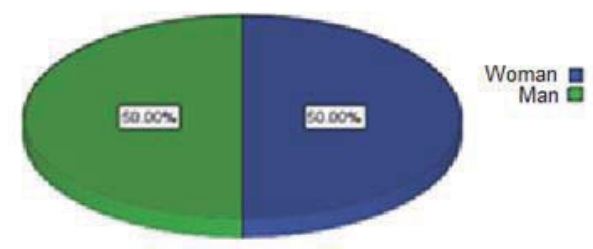

Chart 1: Respondents sex

According to the chart, number of men and women respondent are in a ratio.

2. Age

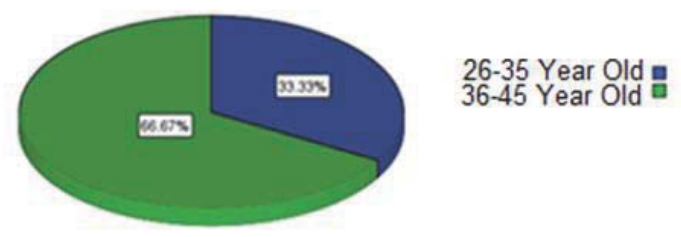

Chart 2: Respondents age

Most ages is between 36 to 45 years.

3. Education

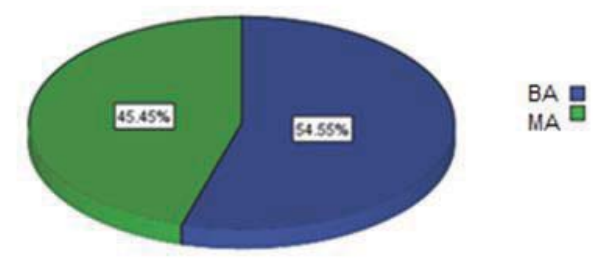

Chart 3: Respondents' education

According to this chart, most percentage of education level has been BA and after that MA.

4. Work experience (duration) 


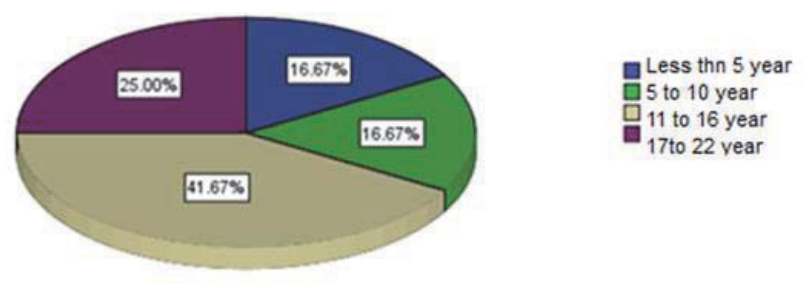

Chart 4: Respondents' 'work experience

Most of the respondents in this section are those between 11-16 years of work experience.

5. Organizational rank

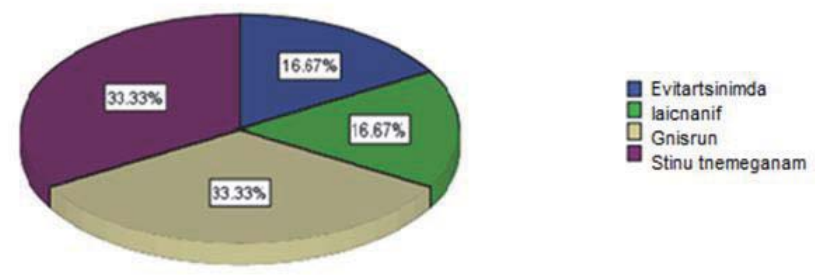

Chart 5: Respondents 'organizational rank

Most of the respondents' frequency in this section is those who have enterprise management and nursing posts.

6. Field of study

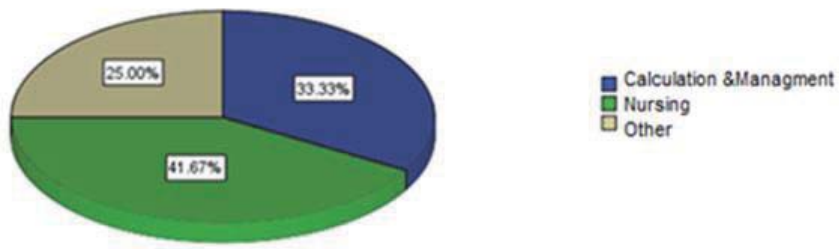

Chart 6: Respondents` field of study

Most respondents` frequency in this section relates to nursing section.

Regarding that balanced score card (BSC) has got 4 dimensions; in this research we will get the main components of each dimension using principal component analysis.

\subsubsection{Financial dimension}

At first we go through evaluating the principal components of financial dimension. As we mentioned before this dimension has got 9 questions that we will offer the results in following. The results of factor analysis have been mentioned here:

Table 3: KMO amount, Bartlet and significant level

\begin{tabular}{|c|c|c|}
\hline KMO & Significant level (sig) & Bartlet \\
\hline 0.000 & 80.287 & 0.446 \\
\hline
\end{tabular}


Based on the findings derived from the factor analysis $\mathrm{KMO}$ amount is equals 0.446 and its Bartlett amount is 80.287 that is at the significant level of over 0.95 and suggests compiled variables being appropriate.

In the following table principal component values and their special values along with the percentage share of variance is provided. Our criteria for extraction of principal components are the ones that have more special values than1.

Table 4: Extracted factors separated by special amount and variance percentage

\begin{tabular}{|c|c|c|c|}
\hline Factor & Variance Percentage of Special Amount & Variance Percentage of Special Amount Frequency & Special Amount \\
\hline 1 & 65.984 & 65.984 & 5.939 \\
\hline 2 & 14.593 & 80.577 & 1.313 \\
\hline 3 & 8.007 & 88.583 & \\
\hline 4 & 4.511 & 93.095 & \\
\hline 5 & 3.288 & 96.383 & \\
\hline 6 & 2.762 & 99.145 & \\
\hline 7 & 0.685 & 99.830 & \\
\hline 8 & 0.156 & 99.986 & \\
\hline 9 & 0.014 & 100.000 & \\
\hline
\end{tabular}

In this table two values have special amount of more than 1 that are selected as main components. In the chart below also main components are offered according to Eskeri chart.

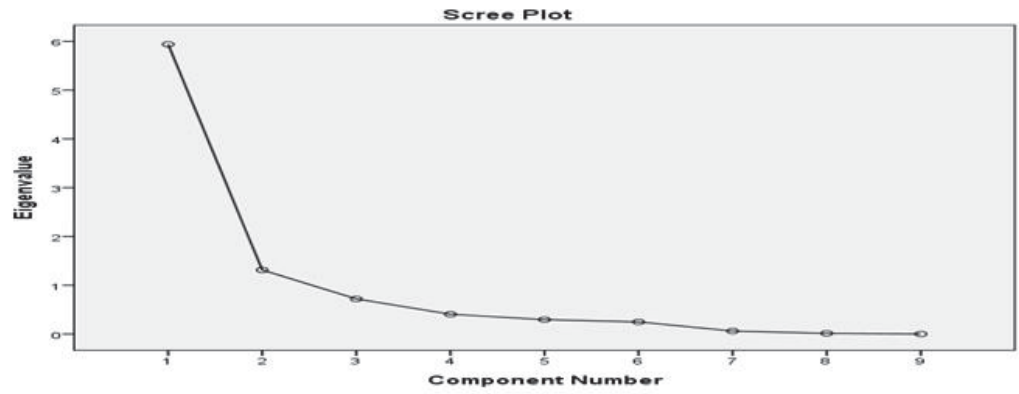

Chart 7: Eskeri chart for financial dimension

As it is evident in the chart two components must be preserved as the main component. But to understand which two main components are, we use Varimaks turning. The results achieved from this turning have been provided in the Appendix that the basis of questions 4 and 3 in the financial questionnaire have been achieved as main components. It means that with BSC performance it is expected that in the financial section

1) Health and medical cost management improves

2) Marketing development and attracting customers.

3) Internal process dimension

The other dimension of this research is internal dimension that includes 12 questions and for decreasing and finding main components, we again use main components. Below are the test results and special values:

Table 5: KMO amount, Bartlet and significant level

\begin{tabular}{|c|c|c|}
\hline KMO & Bartlet & Significant level(sig) \\
\hline 0.756 & 118.25 & 0.000 \\
\hline
\end{tabular}

Based on the findings derived from the factor analysis $\mathrm{KMO}$ amount equals to 0.756 and its Bartlett amount is 118.25 that is at the significant level of over 0.95 and suggests compiled variables being appropriate. In the following table principal component values and their special values along with the percentage share of variance is provided. Our criteria for extraction of principal components are the ones that have more special values than 1. 
Table 6: Derived factors with special amount and variance percentage division

\begin{tabular}{|c|c|c|c|}
\hline Factor & Variance Percentage of Special Amount & Variance Percentage of Special Amount Frequency & Special Amount \\
\hline 1 & 8.126 & 67.716 & 8.126 \\
\hline 2 & 1.430 & 11.917 & 1.430 \\
\hline 3 & 1.030 & 8.580 & 1.030 \\
\hline 4 & 0.642 & 5.353 & \\
\hline 5 & 0.384 & 3.200 & \\
\hline 6 & 0.208 & 1.730 & \\
\hline 7 & 0.092 & 0.764 & \\
\hline 8 & 0.074 & 0.619 & \\
\hline 9 & 0.015 & 0.121 & \\
\hline 10 & $3.081 \mathrm{E}-016$ & $2.567 \mathrm{E}-015$ & \\
\hline 11 & $-4.822 \mathrm{E}-017$ & $-4.018 \mathrm{E}-016$ & \\
\hline 12 & $-3.375 \mathrm{E}-016$ & $-2.813 \mathrm{E} 015$ & \\
\hline
\end{tabular}

In this table 3 components have the special value of 1 that will be selected as the main component. In the following chart also main components are delivered on the basis of Eskeri chart.

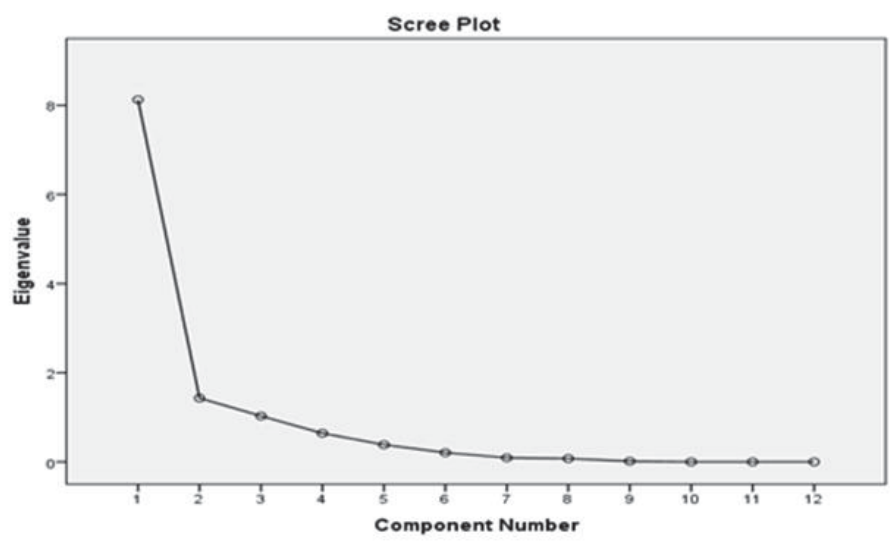

Chart 8: Eskeri chart for internal process

As it is evident in the chart, 3 components must be preserved. But to understand which 3 main components are, we use Varimaks turning. The results achieved from this turning have been provided in the Appendix that the basis of questions 20, 17 and 11 in the internal process dimension questionnaire have been achieved as main components. It means that with BSC performance it is expected that in the internal process section:

1) Having an appropriate organizational chart will be possible

2) Personnel safety standards will improve

3) Having adequate equipment and facilities will be possible

4) Growth and learning dimension

5) Growth and learning dimension includes 7 questions that the results have been specified here:

Table 7: KMO amount, Bartlet and significant level

\begin{tabular}{|c|c|c|}
\hline KMO & Bartlet & Significant level(sig) \\
\hline 0.765 & 92.554 & 0.000 \\
\hline
\end{tabular}

Based on the findings derived from the factor analysis KMO amount equals 0.756 and its Bartlett amount is 92.554 that is at the significant level of over 0.95 and suggests compiled variables being appropriate. 
In the following table principal component amounts and their special values along with the percentage share of variance is provided. Our criteria for extraction of principal components are the ones that have more special values than1.

Table 8: Extracted factors separated by special amount and variance percentage

\begin{tabular}{|c|c|c|c|}
\hline Factor & Variance Percentage of Special Amount & Variance Percentage of Special Amount Frequency & $\begin{array}{c}\text { Special } \\
\text { Amount }\end{array}$ \\
\hline 1 & 76.845 & 76.845 & 6.148 \\
\hline 2 & 12.154 & 89.000 & \\
\hline 3 & 5.703 & 94.703 & \\
\hline 4 & 2.690 & 97.393 & \\
\hline 5 & 1.479 & 98.872 & \\
\hline 6 & 0.751 & 99.623 & \\
\hline 7 & 0.294 & 99.917 & \\
\hline 8 & 0.083 & 100.000 & \\
\hline
\end{tabular}

In this table just one component has special amount of more than 1 and while by existence of just one component, Varimax turning cannot be used, the resulted score of this component has been derived by correlative Matrix that the results have been mentioned in attachment. On this basis, the main component of this dimension is derived from question 22 of the questionnaire. It means by BSC performance it is expected that:

1) Possibility to create appropriate and timely motivation will be provided for the staff

2) Customer dimension

The last raised dimension for BSC implementation relates to customer dimension that here we go through analyzing that.

Table 9: KMO amount, Bartlet and significant level

\begin{tabular}{|c|c|c|}
\hline KMO & Bartlet & Significant level (sig) \\
\hline 0.581 & 174.764 & 0.000 \\
\hline
\end{tabular}

Based on the findings derived from the factor analysis KMO amount equals 0.581 and its Bartlett amount is 174.764 that is at the significant level of over 0.95 , and suggests compiled variables being appropriate. In the following table principal component amounts and their special values along with the percentage share of variance is provided. Our criteria for extraction of principal components are the ones that have special values more than 1.

Table 10: Extracted factors separated by special amount and variance percentage

\begin{tabular}{|c|c|c|c|}
\hline Factor & Variance percentage of special amount & Variance Percentage of Special Amount Frequency & Special Amount \\
\hline 1 & 6.653 & 73.925 & 6.653 \\
\hline 2 & 1.707 & 18.969 & 1.707 \\
\hline 3 & 0.368 & 4.086 & \\
\hline 4 & 0.156 & 1.738 & \\
\hline 5 & 0.079 & 0.882 & \\
\hline 6 & 0.021 & 0.236 & \\
\hline 7 & 0.010 & 0.116 & \\
\hline 8 & 0.004 & 0.040 & \\
\hline 9 & 0.001 & 0.007 & \\
\hline 10 & 6.653 & 73.925 & \\
\hline 11 & 1.707 & 18.969 & \\
\hline 12 & 0.368 & 4.086 & \\
\hline
\end{tabular}

In this table two components have special amount of more than 1 are selected as principle component. In following chart also principle components are delivered on the basis of Eskeri chart. 


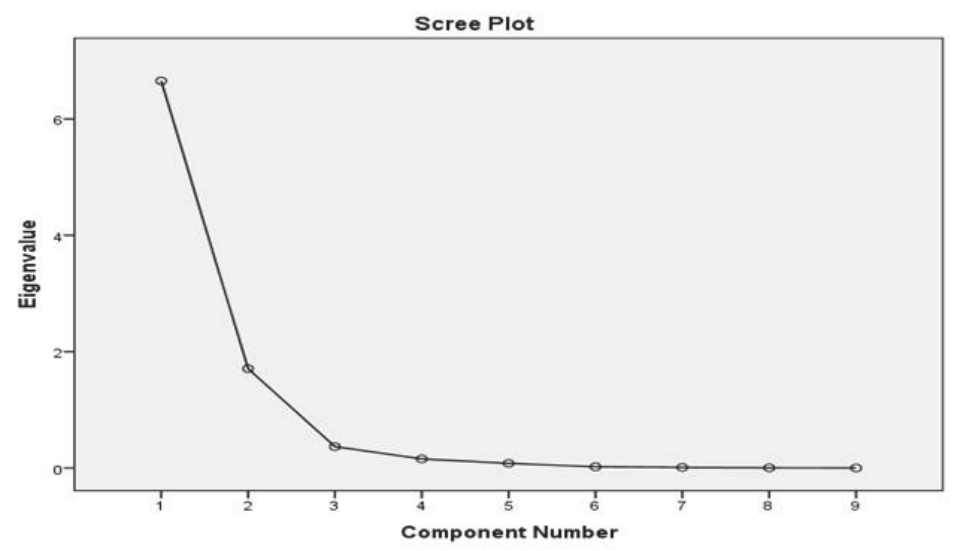

Chart 9: Eskeri chart for customer dimension

The principle components can be seen clearly in the chart too. But to understand which 2 main components are, we use Varimaks turning. The results achieved from this turning have been provided in the Appendix that the basis of questions 30 and 32 in the customer dimension questionnaire have been achieved as main components. It means that with BSC performance it is expected that in the customer dimension:

1) More attention to customer satisfaction.

2) In all sectors, appropriate and decent behavior will be delivered to the patients.

At the end also Freedman test has been used for the raised ranking for the implementation of BSC and test results are offered here in after:

\subsection{Rating implementation of BSC dimensions}

For the study of the influence and way of ranking BSC implementation in target range because delivered replies are on the basis of Likert range, we use non-parametric variance analysis (Friedman) for defining the parameters-rating. According to the Chi-square test, variables have been prioritized. Chi-square test statistic amount is 17.225 with liberty degree of 3 is zero and as the significant level is less than decline level of 0,05 , therefore the assumption of the same effectiveness level of target variables, the declined and as it is clear average of achieved rankings for variables is specified in the following table. It shows that the highest score in terms of environmental safety, is relevant to the population density that from audience point of view is first and foremost important.

Table 11: Ranking BSC implementation dimensions

\begin{tabular}{|l|c|c|}
\hline Dimension & Rankings Average & Rank \\
\hline Financial & 2.50 & 2 \\
\hline Internal process & 3.89 & 1 \\
\hline Growth and learning & 2.17 & 3 \\
\hline Customer & 1.44 & 4 \\
\hline
\end{tabular}

\section{Discussion \& Conclusion}

To identify the main components we used factor analysis that here after will provide obtained results of that analysis.

For financial we introduced 9 parameter to measure it that by using principal component analysis it is expected that two dimensions, health cost management as well as medical costs improvement also marketing improvement and better attracting customer be achieved on the basis of BSC implementation.

On this basis, the value of the implementation of this evaluation covers very well dimensions because it improves the health costs that cut down costs in every organization, especially in the hospitals which is of strategies that each 
manager is looking for and with the implementation of the BSC it can be found. Reducing the costs leads to an increase in the incomes and recovery of other parts that have remained poor because the lack of budget. The other dimension is attracting more patients that again leads to an increase in the hospital income that in spite of these two significant parameters in financial dimension can be fully trusted in BSC implementation to improve the financial dimension.

In the internal process dimension that included 12 questions by using the principal components and with the implementation of the BSC the expectations of getting a proper organizational chart, improving the standard of personnel safety and providing adequate equipment and facilities has been recovered.

According to the achieved results it can be said that BSC implementation leads to organizational chart improvement, applying organizational chart and its being clear is of any organization advantages. Defining this issue that the implementation of BSC will lead to improvements in this sector, the value of this type of evaluation is well specified. Other items in the internal processes have been achieved significant. Improvement in personnel safety and providing adequate equipment and facilities is enough as these two components are most important components for each hospital. For the managers in hospitals who seek for improving these two components, using balanced scorecard can be a great offer.

In growth and learning dimension it is expected that appropriate and timely motivation being provided. Human resource training in each organization is of the most important items to keep up the level of its scientific level, if the implementation of BSC can provide employees appropriate motives. This tool can be used as a effective tool to motivate the staff because an increase in the motivation of employees is of hardest work in the human resources management section and we know that motivated employees are the most important investments of any institution and specially hospitals because if the hospital staff has the necessary motivation, they will have a more appropriate behavior to the customer and the encounter with the hard circumstances will be more encouraging a motivated employee.

In customer dimension, also increasing customer satisfaction and proper and decent deal with patients were extracted as the main components.

According to the components that were achieved on other dimensions of the evaluation card respectively, it is obvious that the results raised leading to customer satisfaction. In the markets nowadays keeping the customer (patients) satisfied is of the most important components and smart managers in every organization seek for keeping their customers satisfied.

Satisfied customer makes the hospital income to increase and staffs' calmness.

The components resulting from the BSC implementation are extremely valuable that it is recommended to the hospitals managers to put it as their work priorities to take advantage of the benefits derived from it and help themselves and their institutions in financial difficulty and, internal problems and so to a large extent.

On the basis of Friedman test also prioritizing the dimensions of BSC implementation was achieved at first for the financial dimension and finally for the customer dimension.

\subsection{Research limitations}

1) The questionnaire tool has fundamental limitations that we can refer to receiving inconsistent responses and lack of precision and sense of responsibility in respondents.

2) Lack of specialists in the field of performance evaluation based on BSC.

\subsection{Suggestions for future researches}

This research is renewable from many aspects. In the first place, the results of this research can be used with other specialists in the navigation unit of University of medical sciences "to falsify it. Meanwhile other methods can be used in order to identify influential variables or even to explain the relations between them. Secondly the present research results can be used in a variety of industries "and answer the questions whether similar factors are identified as a performance evaluation indicators in different industries or not. Thirdly, the relationship between the research 38 paired variables and these criteria influence can be delivered in more complete forum in which the interplay influence of different researching factors on each other can be seen.

Research experience at the hospitals and its result can be a model for identifying and ranking the performance evaluation indicators in other economic enterprises.

It is recommended that the performance evaluation with the balanced scorecard approach in all hospitals and other units also to be performed. 


\section{References}

Adler, M., \& Ziglio, E. (1996). Gazing into the Oracle: The Delphi method and its application to social policy and public health. London: Kingsley Publishers.

Ansari, M., Ostadi, H., \& Motahhari, M. (2009, Fall \& Winter). The impact management on performance of telecommunication company based on BSC model in Isfahan ICT. Iranian Journal of Organization Culture Management, 17(20), 171-190.

Arizi, H., \& Farahani, H. (2009). Research Advanced Methods in Human Sciences. Isfahan, Iran: jahaddaneshgahi, University of Isfahan.

Baldwin, R. (1975). DECISION-MAKING AND THE CONSTITUTIONAL TREATY: WILL THE IGC DISCARD GISCARD? CENTRE FOR EUROPEAN POLICY STUDIES.

Braam, G., \& Nijssen, E. (2004). Performance effects of using the Balanced Scorecard: a note on the Dutch experience. Long Range Planning, International Journal of Strategic Management.

Bremser, W., \& White, L. (2000). An experiential approach to learning about the balanced scorecard. Journal of Accounting Education(18), 241-255.

Davis, S., \& Albright, T. (2004). An investigation of the effect of Balanced Scorecard implementation on financial performance. Management Accounting Research, 15, 135-153.

Helmer, O. (1977, February). Problems in futures research: Delphi and causal cross-impact analysis. Futures (The journal of policy, planning and futures studies), 17-31.

Hoque, Z., \& James, W. (2000). Linking balanced scorecard measures to size and market factors: Impact on organizational performance. Journal of Management Accounting Research(12), 1-17.

Ittner, C., Larcker , D., \& Randall , T. (2003, March). Performance Implications of Strategic Performance Measurement in Financial Services Firms. Social Science Research Network (SSRN). doi:10.2139/ssrn.395824

Kaplan, R. S., \& Norton, D. P. (1992, January-February). The balanced scorecard measures that drive performance. Harvard Business Review.

Kaplan, R., \& Norton, D. (1993, September-October). Putting the Balanced Scorecard to Work. Harvard Business Review, 71(5), 134147. Retrieved from http://www.hbs.edu/faculty/Pages/item.aspx?num=9989

Kaplan, R., \& Norton, D. (2006). Alignment: Using the Balanced Scorecard to Create Corporate Synergies. (B. Zendeh Del, Trans.) Tehran, Iran: Iranian Society of Student Recruitment institutes. Retrieved from http://www.ssri.ir

Malina, M., \& Selto, F. (2001, April). Communicating and Controlling Strategy: an Empirical Study the Effectiveness of the Balanced Scorecard. Social Science Research Network(SSRN). doi:10.2139/ssrn.278939

Maltz, A., Shenhar, A., \& Reilly, R. (2003). Beyond the Balanced Scorecard: Refining the search for organizational success measures. Long Range Planning.

Martinsons, M. G. (1993, June). Outsourcing information systems: A strategic partnership with risks. Long Range Planning, 26(3), 18-25. doi:http://dx.doi.org/10.1016/0024-6301(93)90003-X

Miles, J., \& Banyard, P. (2007). Understanding and Using Statistics in Psychology. London: SAGE Publications Ltd.

Moeieddin, M., Nayeb Zadeh, S., \& Mansouri, E. (2010, Summer). Compare the explanatory power of Traditional and modern criteria on performance evaluation. Iranian Journal of Financial Accounting, 2(6), 121-140. Retrieved from http://fa.journals.sid.ir/View Paper.aspx?ID=113946

Niven, P. (2002). Balanced Scorecard Step-by-Step: Maximizing Performance and Maintaining Results. John Wiley \& sons, Inc n. p.

Wissema, J. (1982, January). Trends in technology forecasting. R\&D Management, 12(1), 27-36. doi:10.1111/j.1467-9310.1982.tb00 480.x

Zareie Matin, H., Jam porazmey, M., reza yazdani, H., \& Sadat Biriaei, H. (2011, Winter). A Survey of the relationship between strategic orientations of enterprise with organizational performance by using balanced scorecard framework. Iranian Journal of Business Management, 2(6). Retrieved from https://jibm.ut.ac.ir/article_22115_0.html 